\title{
TU/e EnNHOUN

\section{Experimental demonstration of control strategies for a gas switching combustion reactor for power production with integrated $\mathrm{CO} 2$ capture}

\section{Citation for published version (APA):}

Zaabout, A., Cloete, S., van Sint Annaland, M., Gallucci, F., \& Amini, S. (2016). Experimental demonstration of control strategies for a gas switching combustion reactor for power production with integrated CO2 capture. Chemical Engineering Research and Design, 111, 342-352. https://doi.org/10.1016/j.cherd.2016.05.007

\section{Document license:}

TAVERNE

DOI:

10.1016/j.cherd.2016.05.007

Document status and date:

Published: 01/01/2016

\section{Document Version:}

Publisher's PDF, also known as Version of Record (includes final page, issue and volume numbers)

\section{Please check the document version of this publication:}

- A submitted manuscript is the version of the article upon submission and before peer-review. There can be important differences between the submitted version and the official published version of record. People interested in the research are advised to contact the author for the final version of the publication, or visit the $\mathrm{DOI}$ to the publisher's website.

- The final author version and the galley proof are versions of the publication after peer review.

- The final published version features the final layout of the paper including the volume, issue and page numbers.

Link to publication

\footnotetext{
General rights

- You may freely distribute the URL identifying the publication in the public portal. follow below link for the End User Agreement:

www.tue.nl/taverne

Take down policy

If you believe that this document breaches copyright please contact us at:

openaccess@tue.nl

providing details and we will investigate your claim.
}

Copyright and moral rights for the publications made accessible in the public portal are retained by the authors and/or other copyright owners and it is a condition of accessing publications that users recognise and abide by the legal requirements associated with these rights.

- Users may download and print one copy of any publication from the public portal for the purpose of private study or research.

- You may not further distribute the material or use it for any profit-making activity or commercial gain

If the publication is distributed under the terms of Article $25 \mathrm{fa}$ of the Dutch Copyright Act, indicated by the "Taverne" license above, please 


\title{
Experimental demonstration of control strategies for a Gas Switching Combustion reactor for power production with integrated $\mathrm{CO}_{2}$ capture
}

\author{
Abdelghafour Zaabout ${ }^{a}$, Schalk Cloete ${ }^{a}$, Martin van Sint Annaland ${ }^{b}$, \\ Fausto Gallucci ${ }^{b}$, Shahriar Amini ${ }^{a, *}$ \\ a Flow Technology Department, SINTEF Materials and Chemistry, Trondheim, Norway \\ ${ }^{b}$ Chemical Process Intensification, Department of Chemical Engineering and Chemistry, Eindhoven University of \\ Technology (TU/e), Eindhoven, The Netherlands
}

\section{A R T I C L E I N F O}

\section{Article history:}

Received 2 November 2015

Received in revised form 4 April

2016

Accepted 5 May 2016

Available online 12 May 2016

\section{Keywords:}

Chemical switching

$\mathrm{CO}_{2}$ capture

Operational strategies

Dynamic fluidized beds

Experimental study

Thermodynamic analysis

\begin{abstract}
A B S T R A C T
This paper reports on operational control strategies for a Gas Switching Combustion (GSC) reactor concept for power generation with integrated $\mathrm{CO}_{2}$ capture. This concept uses a single reactor where air and gaseous fuel feeds are alternated into a bed of oxygen carrier. No external solids circulation is required in this concept and thereby many technical and scale-up challenges that are encountered in the conventional Chemical Looping Combustion processes based on interconnected fluidized bed systems are circumvented.

A first demonstration of this concept has shown that the reactor temperature undergoes large variations across the redox cycle due to the highly exothermic reaction of air with the oxygen carrier. This paper presents and demonstrates the experimental feasibility of a number of heat management techniques implemented in order to minimize the temperature variation and thereby improve the electric efficiency of the GSC concept when integrated into a combined cycle power plant. Three heat management strategies have been devised based on theoretical calculations; two of them involve air feed dilution using nitrogen while the third uses a secondary air injection point to force part of the air feed during the oxidation stage to slip through the bed without reacting with the oxygen carrier.

The three investigated heat management strategies succeeded to greatly reduce the temperature rise across the redox cycle although to different extents. However, the one with the secondary concentrated air injection shows greater economic potential for implementation in the GSC reactor, since it does not require a depleted air recirculation that is required for the two other strategies.
\end{abstract}

(c) 2016 Institution of Chemical Engineers. Published by Elsevier B.V. All rights reserved.

\section{Introduction}

Carbon dioxide Capture and Storage (CCS) is an essential enabling technology to accommodate the global economy's continued reliance on fossil fuels while minimizing the potentially catastrophic long-term impact of climate change (IPCC, 2007; Butt et al., 2012). However, the first generation
CCS technologies (mainly based on amine scrubbing) impose a large energy penalty on the system, thereby reducing the efficiency of a fossil fuel power plant by $14-40 \%$ (Metz et al., 2005). This inefficiency significantly increases the price of electricity and also results in wasteful utilization of dwindling stores of easily accessible conventional fossil fuels. A second generation of $\mathrm{CO}_{2}$ capture technologies is therefore currently

\footnotetext{
* Corresponding author.

E-mail address: shahriar.amini@sintef.no (S. Amini).
}

http://dx.doi.org/10.1016/j.cherd.2016.05.007

0263-8762/@ 2016 Institution of Chemical Engineers. Published by Elsevier B.V. All rights reserved. 


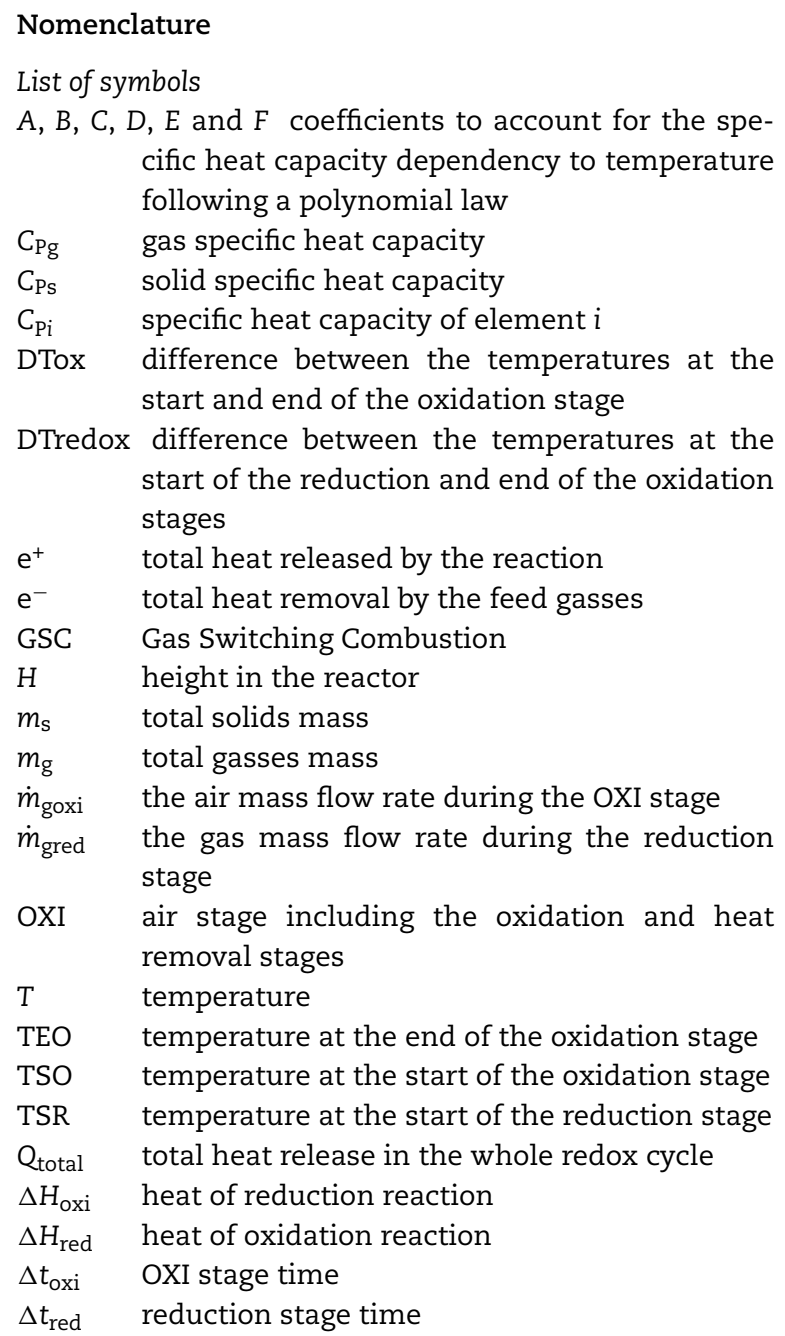

$A, B, C, D, E$ and $F$ coefficients to account for the specific heat capacity dependency to temperature following a polynomial law

$\mathrm{C}_{\mathrm{Pg}} \quad$ gas specific heat capacity

$C_{\mathrm{Ps}} \quad$ solid specific heat capacity

$C_{\mathrm{Pi}} \quad$ specific heat capacity of element $i$

DTox difference between the temperatures at the start and end of the oxidation stage

DTredox difference between the temperatures at the start of the reduction and end of the oxidation stages

$\mathrm{e}^{+} \quad$ total heat released by the reaction

$\mathrm{e}^{-} \quad$ total heat removal by the feed gasses

GSC Gas Switching Combustion

$\mathrm{H}$ height in the reactor

$m_{\mathrm{s}} \quad$ total solids mass

$m_{\mathrm{g}} \quad$ total gasses mass

$\dot{m}_{\text {goxi }}$ the air mass flow rate during the OXI stage

$\dot{m}_{\text {gred }}$ the gas mass flow rate during the reduction stage

OXI air stage including the oxidation and heat removal stages

$T$ temperature

TEO temperature at the end of the oxidation stage

TSO temperature at the start of the oxidation stage

TSR temperature at the start of the reduction stage

$\mathrm{Q}_{\text {total }}$ total heat release in the whole redox cycle

$\Delta H_{\text {oxi }}$ heat of reduction reaction

$\Delta H_{\text {red }} \quad$ heat of oxidation reaction

$\Delta t_{\text {oxi }} \quad$ OXI stage time

$\Delta t_{\text {red }} \quad$ reduction stage time

being developed with the primary purpose of greatly reducing this energy penalty.

Chemical Looping Combustion (CLC) is one of the most promising of these second generation technologies (Lyngfelt et al., 2001; Hossain and de Lasa, 2008; Adanez et al., 2012) with the smallest energy penalty for $\mathrm{CO}_{2}$ capture. The standard CLC configuration uses two reactors where a particulate oxygen carrier circulates between them to transport oxygen from air to fuel. Through the use of the solid oxygen carrier material, the CLC process can dramatically reduce the energy penalty associated with air separation in a standard oxy-fuel process. It even displays a thermodynamic advantage over standard one-step combustion processes, thereby allowing for improved plant efficiency (Ishida et al., 1987).

In order to maximize efficiency, the CLC reactors can be integrated into a combined cycle for power production. This design requires the reactors to operate at elevated pressures using gaseous fuels such as natural gas or syngas from coal gasification. For example, a CLC system integrated in an IGCC operated at a pressure of 20 bar, could achieve efficiencies 3-5\% point higher compared to an IGCC with conventional pre-combustion $\mathrm{CO}_{2}$ capture technology (Spallina et al., 2014; Erlach et al., 2011). The conventional dual circulating fluidized bed CLC concept which has been demonstrated at lab and pilot scales (Kolbitsch et al., 2010; Proell et al., 2009; Johansson et al., 2006; Linderholm et al., 2008; Ding et al., 2012; Kronberger et al., 2004) presents numerous scale-up challenges which will

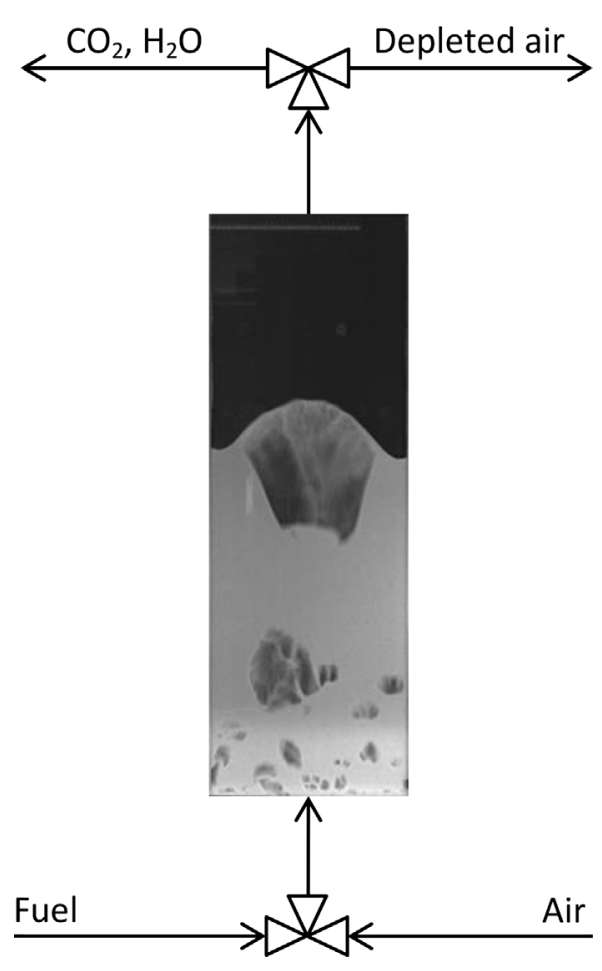

Fig. 1 - Simple illustration of a GSC reactor. Air and fuel streams enter at room temperature and hot process gasses are delivered to the downstream power cycle and $\mathrm{CO}_{2}$ drying and compression unit.

be further magnified under high pressure operation required for integration into combined power cycles.

These challenges have recently led to research into new reactor concepts with no external solids circulation (Gallucci and van Sint Annaland, 2011). This includes CLC concepts based on packed bed technology (Noorman et al., 2007; Hamers et al., 2013), an internal circulating reactor (Zaabout et al., 2014a), a rotating bed reactor (Hakonsen and Blom, 2011) and a gas switching fluidized bed reactor (Zaabout et al., 2013, 2015) which is the subject of this paper. The latter concept, termed Gas Switching Combustion (GSC), is illustrated in Fig. 1 where it is shown that oxidation and reduction of the oxygen carrier material is achieved by alternating air and fuel feeds into a single fluidized bed reactor. Autothermal GSC reactor operation has been demonstrated experimentally without encountering any major technical challenges (Zaabout et al., 2013). The relative ease with which autothermal operation could be achieved offers a first illustration of the potential of the GSC concept to accelerate the scale-up and commercialization of pressurized CLC technology.

The GSC concept is operated similarly to the packed bed CLC process which has recently been demonstrated under pressurized conditions using syngas and an ilmenite-based oxygen carrier (Gallucci et al., 2015). Replacement of the packed bed with a fluidized bed in the GSC concept has a number of important practical advantages. Firstly, the GSC reactor will be able to use very cheap ilmenite ore directly in the reactor which has been shown to operate well in fluidized bed CLC (Cuadrat et al., 2012). The oxygen carrier can also be continuously replenished. In contrast, packed bed operation will require shaped granules which show excellent thermal, chemical and mechanical stability over $\sim 10^{4}-10^{5}$ consecutive cycles. This presents an important technical challenge which is avoided by the GSC concept. Secondly, good mixing in the 
fluidized bed allows for uniform reduction of the bed material as opposed to the sharp reaction front moving through a packed bed. The GSC concept can therefore avoid carbon deposition problems when the material becomes highly reduced by simply shortening the reduction stage. Thirdly, the fuel can react throughout the entire height of the fluidized bed whereas a sharp reaction front must be maintained in the packed bed to avoid fuel slippage. This allows for larger gas flowrates in the GSC concept. On the other side, the most important drawbacks of the GSC concept are (1) undesired gas mixing when switching between air and fuel, (2) particle attrition which will require high-temperature filtration to protect the downstream gas turbine, and (3) potentially large temperature variations across the cycle. The latter is viewed as the most important challenge because it can substantially reduce plant efficiency. Minimizing this temperature variation is therefore the object of this study.

Similarly to packed bed CLC, the GSC concept will employ a cluster of standalone reactors in order to provide a sufficiently steady stream of process gasses to downstream process units (Zaabout et al., 2013). Such standalone reactors are relatively easy to pressurize and scale up, thereby avoiding the major barriers to application of CLC in high-efficiency combined cycle power plants. On the other hand, the switching concept introduces a new technical challenge in the form of valves which must be capable of switching the high temperature and pressure outlet gasses between the gas turbine and the $\mathrm{CO}_{2}$ treatment facilities.

The integration of the GSC concept into integrated gasification combined cycles was recently investigated to reveal the potential for high electric efficiencies $(41.9 \%)$ and $\mathrm{CO}_{2}$ capture ratios (over 90\%) (Cloete et al., 2015a). However, without advanced heat management strategies, it was not possible to keep both the electric efficiency and $\mathrm{CO}_{2}$ capture ratio at a high level. The transient GSC operating cycle involves a rapid temperature increase during the exothermic oxidation stage followed by a decrease during the subsequent heat removal and reduction stages. This transient temperature variation implies that the average reactor outlet temperature to be sent to the gas turbine must be lower than the maximum safe operating temperature, thus leading to sub-optimal efficiencies. This inefficiency can be reduced by running shorter cycles, thereby reducing the magnitude of the temperature variation, but more frequent switching between air and fuel in a fluidized bed reactor leads to increased contact between $\mathrm{N}_{2}$ and $\mathrm{CO}_{2}$, thus reducing the $\mathrm{CO}_{2}$ capture ratio (Cloete et al., 2015a).

It therefore becomes important to maximize the length of the transient GSC cycle, while minimizing the degree of temperature variation. One possible solution is the use of oxygen carriers with an exothermic reduction reaction supported on materials with high specific heat capacity (Zaabout et al., 2015). However, the most economically attractive oxygen carrier for the integration of GSC into integrated gasification combined cycles, Ilmenite, displays a high degree of temperature variation across the cycle. For this reason, the aforementioned thermodynamic study of the GSC-IGCC concept (Cloete et al., 2015a) investigated advanced heat management strategies using a large stream of recirculated $\mathrm{N}_{2}$ (depleted air). These strategies successfully achieved both high electric efficiencies and $\mathrm{CO}_{2}$ capture ratios.

Given the promise shown by these advanced heat management strategies investigated numerically using both phenomenological and CFD modeling approaches (Cloete et al., 2015a,b), this paper will present experimental demonstrations of these strategies in a lab scale reactor. In addition, a heat management strategy which could produce the same positive effect without the need for a $\mathrm{N}_{2}$ recycle stream is also investigated. This strategy makes use of a concentrated air injection in order to limit gas/solid contact so that the required heat can be extracted while only a fraction of the available oxygen is reacted. The theoretical background behind these operational strategies is first discussed using heat balance calculations.

Finally, another important parameter to consider is the number of reactors in the cluster operating simultaneously in order to supply steady hot gas stream to the downstream power cycle; this number is dependent to the ratio between the length of the oxidation and reduction stages (oxi/red time ratio). Devising operational strategies which enable controlling this parameter is essential for setting the desired number of reactors to be used in the cluster for process optimization and control purposes.

\section{Theoretical background}

Heat balance calculations have been carried out to investigate the temperature behavior in the GSC reactor across the redox cycle. This investigation will pave the way for devising heat management strategies aiming to minimize the temperature variation in the GSC reactor across the redox cycle. For this purpose, three temperatures marking transitions between the different stages involved in the GSC concept are determined, viz. the temperature at the start of the reduction stage (TSR), the temperature at the start of the oxidation stage (TSO) and the temperature at the end of the oxidation stage (TEO). Two measures will be determined in order to quantify the extent of temperature variations involved in the GSC concept: the difference between the temperatures at the start and end of the oxidation stage, DTox, and the difference between the temperatures at the start of the reduction and end of the oxidation stages, DTredox.

A Ni-based oxygen carrier is used for both the heat balance calculations and the experimental study which will follow in the next section. This oxygen carrier exhibits a large temperature variation across the redox cycle similar to the typical temperature rise found with ilmenite which is considered as one of the main candidates for IGCC CLC applications (Spallina et al., 2014; Cloete et al., 2015a). Ni-based oxygen carrier is therefore a good example to test the efficiency of heat management strategies in minimizing the temperature rise. The conclusions made for Ni-based oxygen carrier are applicable to the GSC reactor operating with ilmenite or with any other oxygen carriers which exhibit large temperature variations.CO is used as the reducing gas due to its good reactivity with Ni-based oxygen carrier (CO showed better conversion than methane when used with a Ni-based oxygen carrier (Zaabout et al., 2015)) and is also one of the main components of syngas if the GSC is to be integrated in an IGCC. Air is used as the oxidizing gas. Calculations are done for a $\mathrm{CO}$ feed of $180 \mathrm{~s}$ at a flow rate of $50 \mathrm{~N} \mathrm{l} / \mathrm{min}$ (both $\mathrm{CO}$ and air are fed at room temperature) and $2500 \mathrm{~g}$ of oxygen carrier (similar to the experimental operating conditions). The mass of fuel combustion products and depleted air following the reduction and oxidation reactions in Table 1 are determined. Temperature dependent specific heat capacities were used in the calculations according to Eq. (3) and data provided in Robie and Hemingway (1995).

The following methodology was employed: Firstly, the desired temperature rise, DTredox, in the cycle is set by fixing the targeted temperature at the end of the oxidation stage 
Table 1 - Active content in the nickel based oxygen carrier, its redox reaction equations and the corresponding heat of reactions.

\begin{tabular}{llll} 
& Total/Active $\mathrm{MeO}$ content $(\mathrm{wt} \%)$ & Reactions equations & $\Delta \mathrm{H}_{0}(\mathrm{~kJ} / \mathrm{mol})$ \\
\hline $\mathrm{Ni} / \mathrm{NiO}\left(\mathrm{Al}_{2} \mathrm{O}_{3}\right)$ & $63 / 37$ & $\mathrm{CO}+\mathrm{NiO} \leftrightarrow \mathrm{Ni}+\mathrm{CO}_{2}$ & -43.3 \\
& & $\mathrm{O}_{2}+2 \mathrm{Ni} \leftrightarrow 2 \mathrm{NiO}$ & -479.4 \\
& & $\mathrm{CO}+0.5 \mathrm{O}_{2} \leftrightarrow \mathrm{CO}_{2}$ & -283 \\
\hline
\end{tabular}

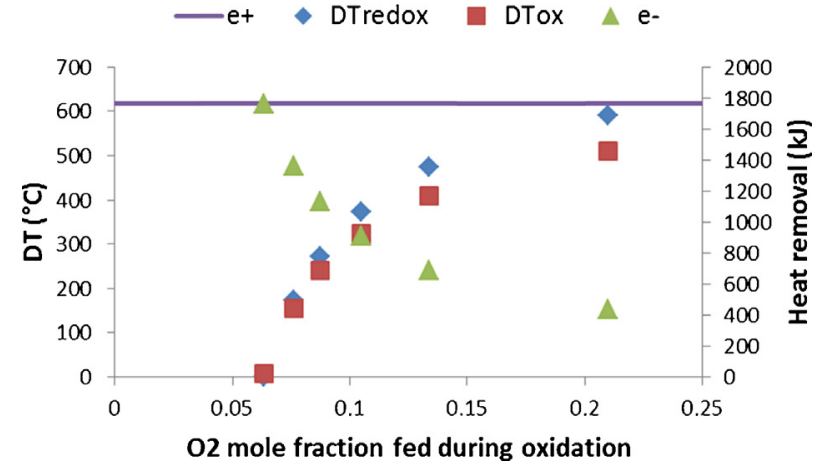

Fig. 2 - Temperature rise across both the oxidation stage (DTox) and the redox cycle (DTredox) as a function of the $\mathrm{O}_{2}$ mole fraction in the gas feed during the oxidation stage. The corresponding total heat removal by the feed gasses $\left(\mathrm{e}^{-}\right)$and total heat released by the reaction $\left(\mathrm{e}^{+}\right)$are also plotted.

(TEO = $1273 \mathrm{~K}$ in this study; this relatively low temperature was chosen to enable direct comparison with experimental results shown and discussed in Sections 3 and 4 and the conclusions will be qualitatively similar for the actual process at higher temperatures and pressures) and the temperature at the start of the reduction stage. Eq. (1) is then solved in order to determine the temperature at the start of the oxidation stage, while Eq. (2) is used to determine the required $\mathrm{O}_{2}$ mole fraction in the gas feed in the oxidation stage in order to maintain the desired temperature rise (it was assumed that the gases are heat up from room temperature to the average temperature between the start and the end of each stage). The total heat removal by the gas feed during the redox cycle for each desired temperature rise is also quantified. The different entities are plotted in Fig. 2 together with the total heat released across the redox cycle.

$\int_{\mathrm{TSR}}^{\mathrm{TSO}} m_{\mathrm{S}} C_{\mathrm{Ps}}(\mathrm{T}) d \mathrm{~T}+\int_{298}^{(\mathrm{TSO}+\mathrm{TSR}) / 2} m_{\mathrm{g}} C_{\mathrm{Pg}}(\mathrm{T}) d \mathrm{~T}=\Delta H_{\mathrm{red}}$

$\int_{\text {TSO }}^{\text {TEO }} m_{\mathrm{S}} C_{\mathrm{PS}}(\mathrm{T}) d \mathrm{~T}+\int_{298}^{(\mathrm{TEO}+\mathrm{TSO}) / 2} m_{\mathrm{g}} C_{\mathrm{Pg}}(\mathrm{T}) d \mathrm{~T}=\Delta \mathrm{H}_{\text {oxi }}$

$C_{\mathrm{Pi}}=A T^{5}+B T^{4}+C T^{3}+D T^{2}+E T+F$

Fig. 2 shows that the temperature variation across the cycle can be controlled over a wide range by changing the $\mathrm{O}_{2}$ mole fraction in the oxidizing gas. Since TEO is kept constant, TSR and TSO will be shifted to higher values if a lower temperature rise is achieved through air dilution, implying that the reactor will be operating at higher temperatures across the redox cycle. The result will be higher process efficiencies and lower mass throughputs, thus increasing the economic attractiveness of the GSC concept.

For this particular case, the total heat removal by the cold feed gasses reaches the heat release from the reaction
(DTredox $=0^{\circ} \mathrm{C}$ in this condition) at an $\mathrm{O}_{2}$ mole fraction equal to 0.063 . This corresponds to $70 \%$ dilution of air, implying that $70 \%$ of the depleted air will need to be recirculated and re-injected with air feed in the oxidation stage. A very small temperature rise of $7^{\circ} \mathrm{C}$ across the oxidation stage (DTox) will be achieved in these conditions. If the $\mathrm{O}_{2}$ mole fraction is further lowered, the reactor will not be able to maintain the targeted maximum temperature.

In the light of the promising outcomes from the theoretical calculations, heat management techniques can be designed in order to control the temperature rise in the redox cycle. Such a technique will involve controlled gas injection during the oxidation stage with the restricted role of heat removal from the reactor in order to achieve minimized temperature rise across the redox cycle. The most straightforward strategy is to dilute the air feed across the oxidation stage as was done in Fig. 2. As an alternative, undiluted air can be injected in a very concentrated manner in order to achieve large $\mathrm{O}_{2}$ slippage through the bed without being reacted with the oxygen carrier. Since gas/particle heat transfer is generally a lot faster than heterogeneous reaction rates (the time to heat a given volume of air to the particle temperature is about 4 orders of magnitude smaller than the time to consume all available oxygen through reaction), this strategy should be able to remove the required heat without generating excessive heat through reaction.

The following sections will experimentally evaluate these heat management strategies. The aim is to demonstrate experimentally the feasibility of such heat management technique implementation and to test their efficiency in terms of temperature rise reduction. The same pseudo $2 \mathrm{D}$ reactor used in the experimental demonstration of the GSC concept is used in this study (Zaabout et al., 2013, 2015). Conclusions drawn from the pseudo 2D reactor are applicable to the real $3 \mathrm{D}$ reactor.

\section{Experiments and methods}

\subsection{Experimental set up}

The experimental setup (Fig. 3) consisted of a pseudo-2D vertical column with a height of $1.5 \mathrm{~m}$, a width of $0.3 \mathrm{~m}$ and a depth of $0.015 \mathrm{~m}$. The pseudo-2D configuration was selected for the purpose of extracting local experimental data for detailed CFD model validation and was based on a cold flow unit with similar dimensions (Cloete et al., 2013). The reactor column was made from Inconnel 600 in order to withstand the harsh conditions of high temperatures (up to $1000^{\circ} \mathrm{C}$ ) and reacting gas-solids flows. Measurement holes were created on the reactor front for local data collection. The same holes are used as a secondary gas injection point. A ceramic porous plate with 40 micron pores and $7 \mathrm{~mm}$ thickness was used as the gas distributor. A freeboard was added to the top of the main reactor body in order to prevent particle entrainment. The setup was equipped with four electrical heaters (Thermcraft Inc.) installed on the back of the reactor in order to heat the reactor to the target temperature (also referred to as the operating 


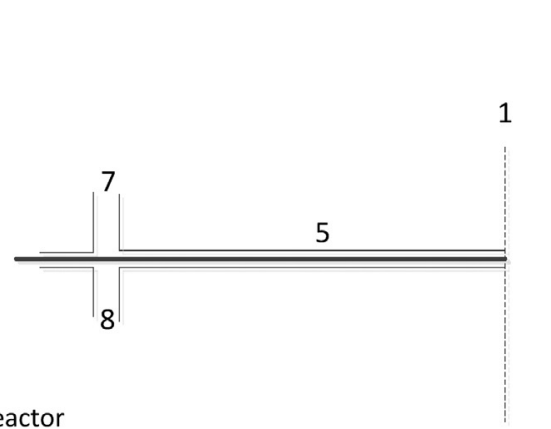

2: $1.3 \mathrm{~cm}$ void space between the reactor and heaters

3: Heaters

4: Blanket insulation

5: Multi-tasking measurement tube

6: $30 \mathrm{~cm}$ thermocouple inserted towards the reactor wall

7: Pressure sampling

8: Gas sampling through a capillary tube connected to the MS

9: A secondary air injection line

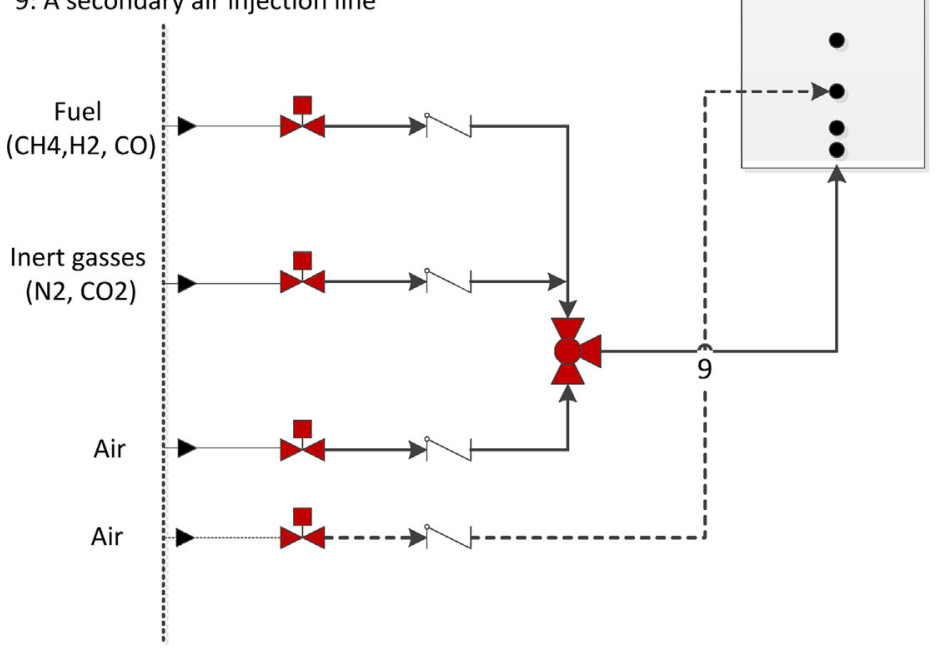

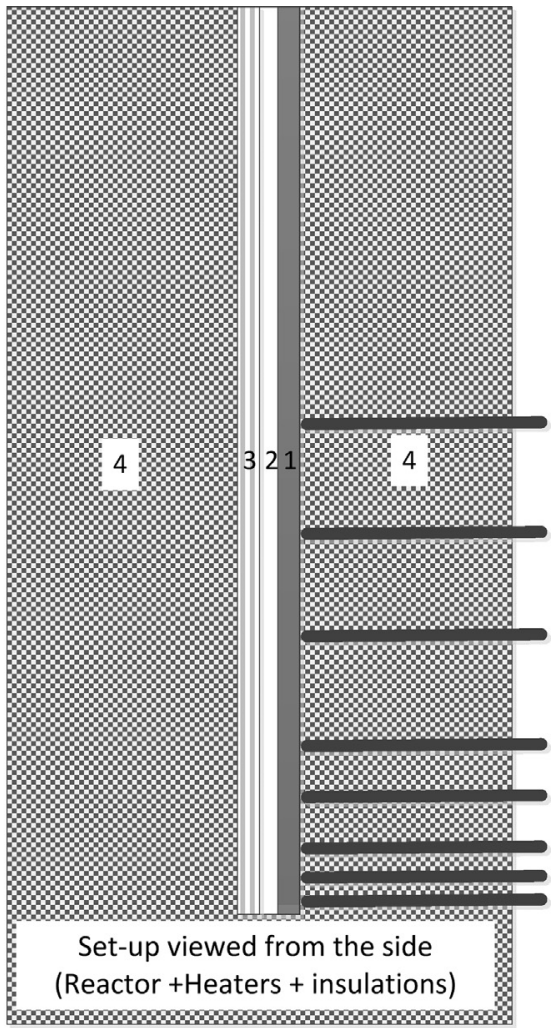

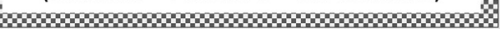

Fig. 3 - Schematic representative of the experimental set up.

temperature). Each of these heaters is controlled separately allowing for full control of the heat supply to the desired region in the reactor. Blanket insulation ( $25 \mathrm{~cm}$ thickness) was used to maintain the heat in the system.

Three mass flow controllers (Bronkhorst BV) were used for the main gas feeds into the reactor in addition to a fourth mass flow controller which was used for a secondary air injection. The three gas lines for the main gas feeds gather at a threeway electrical valve installed before reaching the distributor. This three-way electrical valve is used to switch between feed gasses. A cooler was positioned at the outlet of the reactor to cool down the stream of hot gasses before it is sent to the vent.

The gas composition was measured using a Mass Spectrometer from MKS Instruments Inc. and the temperature was measured in each port along the entire front of the reactor using type $\mathrm{K}$ thermocouples. All the measurement instruments, flow controlling devices were controlled through a Labview application. The Labview application was also used for data acquisition and storage. Further details about the experimental setup can be found in (Cloete et al., 2013; Zaabout et al., 2014b).

\subsection{Operation}

All GSC demonstration experiments reported in this paper were completed with an amount of oxygen carrier material corresponding to a $0.3 \mathrm{~m}$ static bed height in the reactor. Nickel oxide particles supported on $\mathrm{Al}_{2} \mathrm{O}_{3}$ (manufactured by VITO) were used as the oxygen carrier. The $\mathrm{NiO} / \mathrm{Al}_{2} \mathrm{O}_{3}$ ratio is $65 / 35$ and the particle size cut-offs D10, D50 and D90 were determined to be $117.4,161.7$ and $231.3 \mu \mathrm{m}$ respectively. About $37 \%$ of the final batch of particles consists of free NiO which is available for reaction. The powder has a loosely packed density of $1950 \mathrm{~kg} / \mathrm{m}^{3}$ and a tapped density of $2166 \mathrm{~kg} / \mathrm{m}^{3}$. This oxygen carrier was selected because it has been successfully used in previous studies (Cloete et al., 2013; Bolhar-Nordenkampf et al., 2009; Cho et al., 2004).

A typical redox cycle in the GSC concept contains three stages: the reduction, oxidation and heat removal stage. In the following discussion, the oxidation and heat removal stages will be referred to as the OXI stage since the GSC concept allows these two stages to be completed sequentially with identical feed conditions.

In order to achieve autothermal operation, the reactor is first heated up externally to the target temperature before starting the gas switching experiments. When heaters are switched off a pure gaseous fuel is fed for a fixed amount of time referred to as the "fuel time" to reduce the oxygen carrier. A feed with pure air follows to oxidize the reduced oxygen carrier and remove the heat which builds up from the highly exothermic oxidation reaction. Five seconds purging with pure nitrogen is applied between the air and the fuel stages to avoid 
direct contact between fuel and air and thereby eliminate the risk of explosion. As mentioned earlier, $\mathrm{CO}$ was used as a fuel gas for the reduction stage.

Experiments were carried out at temperatures much lower than the typical ones found in real power plant operation due to large heat losses from the lab-scale reactor. Autothermal operation of the GSC reactor with long cycles to achieve high $\mathrm{CO}_{2}$ capture ratio (as shown in (Cloete et al., 2015a)) was not possible due to the large heat loss rates. Yet, the main goal of this experimental campaign is to demonstrate the feasibility of implementation of operational strategies to control the GSC reactor. This goal can be achieved at any temperature where stable autothermal operation of the GSC reactor can be ensured; conclusions drawn from the lower temperature experimental campaign are still valid when the GSC reactor is operating under real power plant operation temperatures. It should also be mentioned that the Ni-based oxygen carrier used in this study is highly reactive even at the relatively low temperatures used in this study (Zaabout et al., 2014b), so it was possible to carry out stable GSC cycles under this temperature.

Throughout the study, all temperature measurements are taken at $0.3 \mathrm{~m}$ in the central axis of the reactor. Temperature variations at this point are followed throughout the experiment and used to determine the start and end of the redox cycles. Gas species measurements are taken at a height of $0.7 \mathrm{~m}$ which is a point in the freeboard well above the expanded bed. All experiments have been repeated for three cycles for credibility.

The pressure along the height of the reactor was measured regularly in order to quantify the bed weight and to inspect any unexpected loss of particles caused by elutriation of particles due to gas expansion when the reactor reaches higher temperatures.

\section{GSC reactor control}

The aim of this section is to define operational strategies for controlling the GSC reactor and gain practical experience with the experimental implementation of these strategies. Two important considerations will be investigated: (i) the oxi/red time ratio must be an integer so that the reactor can function as part of a reactor cluster. Additionally, by controlling this parameter, the desired number of reactors in the cluster can be customized for GSC optimization purpose; (ii) the reactor output gasses should be kept as close as possible to a constant temperature in order to ensure high power cycle efficiency.

The first point will be investigated by changing the fuel flow rate while maintaining the air feed flow rate $(50 \mathrm{~N} \mathrm{l} / \mathrm{min})$ and the fuel time constant (180 s). The air feed flow rate correspond to a fluidization velocity of $0.41 \mathrm{~m} / \mathrm{s}$ which falls well in the bubbling regime as the estimated minimum fluidization and transition velocities are 0.03 and $3.3 \mathrm{~m} / \mathrm{s}$ respectively according to the correlations of Bi \& Grace (Bi and Grace, 1995). The second point will be investigated by implementing a number of heat management techniques. The different techniques are compared based on their ability to minimize the temperature variation across the redox cycle and ease of technical implementation and manipulation.

\subsection{Control of the oxi/red time ratio}

The effect of the fuel flow rate on the length of the redox cycle and consequently the oxi/red time ratio parameter was

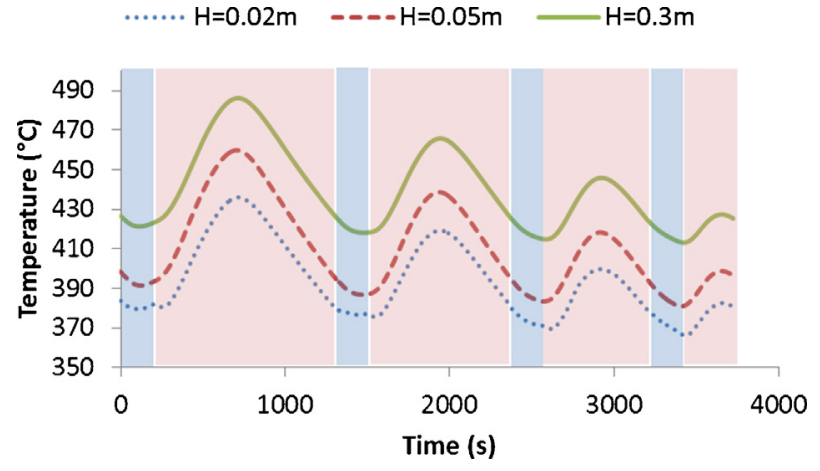

Fig. 4 - Transient temperature at three different axial positions where the fuel flow rate has been decreased in consecutive redox cycles. The blue area represents the reduction stage while the pink area represents the $O X I$ stage (the OXI stage includes both oxidation and heat removal stages).

investigated (the oxi/red time ratio refers to the ratio between the obtained OXI time as measured experimentally and the fuel time fixed as input of the study). The air feed flow rate was maintained constant at the maximum feed rate without significant particles elutriation. The oxi/red time ratio for each fuel flow rate was determined and plotted against the fuel/air flow rate ratio. It should be noted that the oxi/red time ratio also represents the number of reactors in the cluster operating under the OXI stage, implying that the total number of reactors in the cluster will be equal to the oxi/red time ratio + 1 (Cloete et al., 2013).

Parallel heat balance calculations were performed to collect the oxi/red time ratio for the same flow conditions used experimentally. The theoretical OXI time was calculated with and without inclusion of heat losses by solving Eq. (4). Note that the total reaction heat generated in the redox cycle is removed by the gas feed (first term on the right) and heat losses from the reactor (second term on the right) over the entire redox cycle. The heat loss rate is a function of the difference between the reactor and room temperatures, $\Delta T$. Data of transient reactor temperature collected at different heights in the reactor, while the heaters were off, was used to extract the heat loss rate function, $f(\Delta T)$. No gasses were fed into the reactor during temperature data collection to ensure that the temperature drop was only caused by heat losses from the reactor. The experimentally measured heat loss rate was fitted to a polynomial function as shown in Eq. (5).

The OXI time $\Delta t_{\text {oxi }}$ was calculated by solving Eq. (4), and the resulting oxi/red ratio was plotted in Fig. 5 with and without inclusion of heat losses together with the experimentally measured oxi/red ratio. The gas and solids heat capacities were assumed to be 1.1 and $770 \mathrm{~J} /(\mathrm{kg} \mathrm{K})$ respectively.

$$
\begin{aligned}
Q_{\text {total }}= & \left(\dot{m}_{\mathrm{g}, \text { red }} \Delta t_{\text {red }}+\dot{m}_{\mathrm{g}, \text { oxi }} \Delta \mathrm{t}_{\mathrm{oxi}}\right) C_{\mathrm{Pg}} \Delta \mathrm{T}+m_{\mathrm{s}} C_{\mathrm{Ps}} f(\Delta \mathrm{T}) \\
& \times\left(\Delta \mathrm{t}_{\mathrm{red}}+\Delta \mathrm{t}_{\mathrm{oxi}}\right) \\
f(\Delta \mathrm{T})= & 3.71 \times 10^{-11} \Delta \mathrm{T}^{4}-6.11 \times 10^{-9} \Delta \mathrm{T}^{3}+3.3 \times 10^{-6} \Delta \mathrm{T}^{2} \\
& -4.55 \times 10^{-4} \Delta \mathrm{T}
\end{aligned}
$$

The transient temperature profiles found for the different fuel flow rates are plotted as a function of time (Fig. 4). As mentioned previously, the typical temperature profile for a 


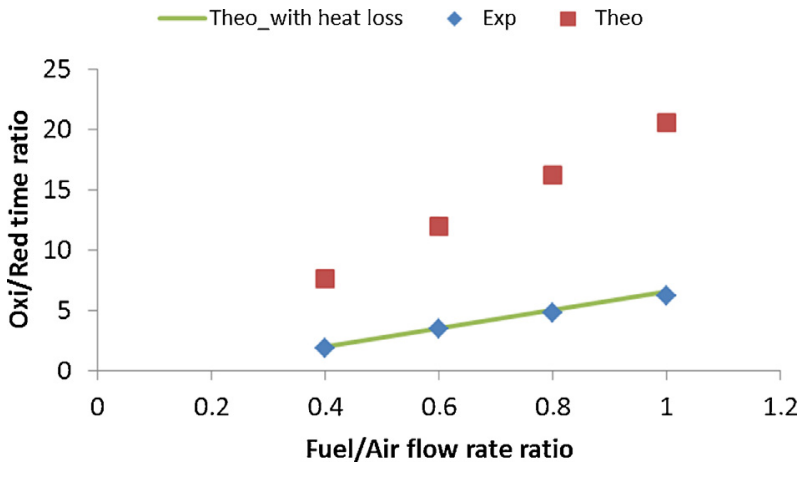

Fig. 5 - Oxi/red time ratio plotted against the fuel/air flow ratio. The theoretical predictions accounting for the heat losses from the reactor match well the experimental findings.

redox cycle in the GSC reactor shows a slight decrease during the reduction stage (the reduction reaction of $\mathrm{NiO}$ with $\mathrm{CO}$ is slightly exothermic, but the slight decrease in the temperature shown is due to the heat losses) then followed by a strong increase due to the highly exothermic oxidation reaction. The maximum is reached close to the end of the oxidation stage. A drop in the temperature follows with further air feed for heat removal. Similar behavior is shown for the consecutive redox experiments with lower fuel flow rates. This consequently resulted in shorter redox cycle times and lower temperature rises.

The experimentally measured oxi/red time ratio was found to increase linearly with the fuel/air flow rate ratio (Fig. 5). The relation linking both entities could however be used as a tool to set the desired total number of reactors in the cluster by setting a proper fuel/air flow rate ratio. This would however depend on a number of factors such as the operating temperatures and pressures in addition to the heat losses involved; Fig. 5 clearly shows the large difference between the theoretical predictions without accounting for the heat losses and the experimental findings caused by the large heat losses in the experimental set-up. However, the inclusion of heat losses estimated from the experimentally observed temperature decrease after shutting off the heaters and feed gas produced a good match with experiments (Fig. 5).

\subsection{Heat management strategies}

Heat management techniques have been designed based on the outcomes of the theoretical calculations carried out in Section 2. It has been shown that dilution of the air feed in the oxidation stage, in a way to extend the oxidation stage to cover the heat removal stage, could greatly minimize the temperature variation across the redox cycle. These theoretical outcomes have been translated into three different heat management techniques, of which two use nitrogen for diluting the air feed in the OXI stage and a third one uses a secondary air injection point into the bed where the role is to push part of the $\mathrm{O}_{2}$ in the feed air to escape through the bed without reacting with the oxygen carrier, thereby playing the role of a heat removal agent. It is worth mentioning that power plant calculations of the GSC reactor integrated in an IGCC have shown that heat management strategies with $\mathrm{N}_{2}$ addition in the OXI stage could significantly increase the plant electric efficiency (from 38.2\% to $41.6 \%$ ) (Cloete et al., 2015a,c).

It should be noted that the nitrogen recycle loop required for cases 1 and 2 would add significant complexity and cost to the plant. Nitrogen recycling will require an $\mathrm{N}_{2}$ recycle cooling system as well as a gas cycle compressor with a higher inlet temperature and volume flow rate. Avoidance of these complexities is the motivation behind the concentrated injection proposed in case 3 .

The technical feasibility of these heat management strategies were tested experimentally and compared to a reference case. A constant gas flow rate of $50 \mathrm{Nl} / \mathrm{min}$ was applied for both the reduction and OXI stages and a reduction time of $180 \mathrm{~s}$ was applied. The following four cases have been investigated:

- A reference case (referred to in the rest of the document as "reference"), where undiluted air was fed for the whole OXI stage.

- Case 1, where the air feed was diluted with a constant flow of nitrogen during the OXI stage.

- Case 2, where pure air was fed in the beginning of the OXI stage to reach the maximum targeted temperature in the cycle and then air feed was diluted with nitrogen in order to maintain constant temperature for the remaining OXI time.

- Case 3, where concentrated air injection was applied through a secondary injection point: part of the air feed in the OXI stage was injected through an injection point at the central axis of the reactor. As mentioned previously, injecting air in a very concentrated manner will cause large $\mathrm{O}_{2}$ slippage through the bed without being reacted with the oxygen carrier.

For case 3, two factors are expected to influence the bed hydrodynamic behavior and eventually the reactor performance. These factors are the axial position of the secondary injection point and the percentage of the concentrated air injection from the total air feed. The effects of these two factors were investigated and are first discussed in the following section, followed by a comparison of the performances of the different heat management strategies.

\subsubsection{Heat management through concentrated air injection}

This section is devoted to case 3 , where the effect of the axial injection position and the percentage of the concentrated injected air from the total air feed in the OXI stage on the temperature rise control is investigated and discussed.

4.2.1.1. Effect of the injection position. The effect of the axial position of the secondary air injection on the temperature variation was investigated, where $80 \%$ from the total air feed was fed through the secondary injection point for three different axial positions, viz. 0.02, 0.05 and $0.10 \mathrm{~m}$ above the plenum; the remaining percentage was feed as usual from the bottom of the reactor through the porous plate. The transient temperature and $\mathrm{O}_{2}$ mole fraction profiles were collected for the three experiments and compared to the reference case which does not involve any heat management strategies.

As can be seen in Fig. 6, although the concentrated injection reduced the degree of temperature variation across the cycle relative to the reference case, the position of the injection did not have a significant effect. This result suggests that the envisioned mechanism of substantial $\mathrm{O}_{2}$ bypass did not take place, but that other factors related to changes in the bed hydrodynamics played an important role.

To better illustrate the effect of a secondary injection on the reactor performance, the transient $\mathrm{O}_{2}$ mole fraction profiles are plotted in Fig. 7. The typical $\mathrm{O}_{2}$ consumption trend 


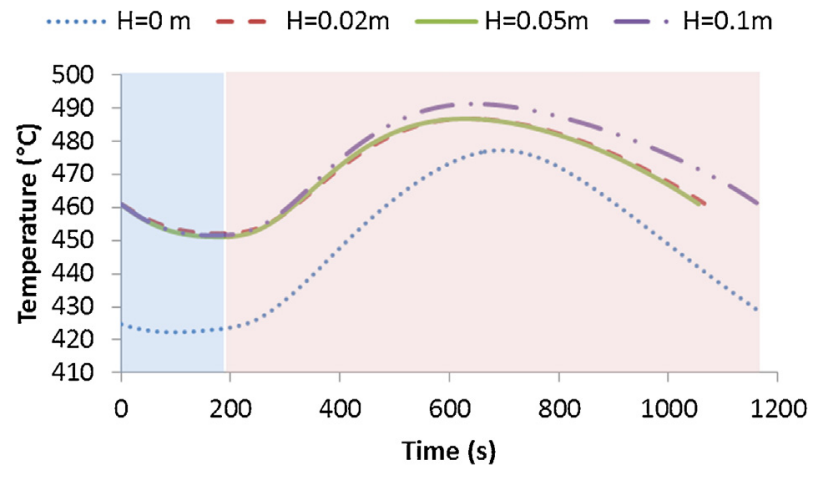

Fig. 6 - Transient temperature across the redox cycle: effect of the concentrated air injection at different axial positions. The blue area represents the reduction stage, while the pink area represents the OXI stage (the OXI stage includes both oxidation and heat removal stages).

in the reference case (indicated in Fig. 7 with $\mathrm{H}=0 \mathrm{~m}$ ) consists of distinguishable phases: the first phase is characterized by close-to-complete conversion of $\mathrm{O}_{2}$ which takes place in the first $200 \mathrm{~s}$ of the OXI stage. The second phase is characterized by an increasing amount of unconverted $\mathrm{O}_{2}$ coming out of the reactor. A third phase with pure heat removal follows starting from around $600 \mathrm{~s}$ from the start of the OXI stage; this is the phase referred to as the heat removal stage in the GSC concept (the three phases forms what we call the OXI phase which refers to the air stage).

When the secondary concentrated air injection was applied, the first phase (complete $\mathrm{O}_{2}$ conversion) was shortened by half independently of the injection position. A second phase with increasingly reduced $\mathrm{O}_{2}$ conversion follows and extends over the remaining time of the OXI stage; no pure heat removal phase was found in the concentrated air injection case. This trend could be caused by the combined influences of a reduced gas residence time due to the concentrated injection and imperfect gas mixing. The gradual increase in the $\mathrm{O}_{2}$ concentration above the reactor bed is the result of the gradual decrease in oxygen carrier reactivity as the degree of oxidation increases. A shorter gas residence time in the central plume resulting from the concentrated injection would result in earlier $\mathrm{O}_{2}$ breakthrough. In addition, reduced gas back-mixing

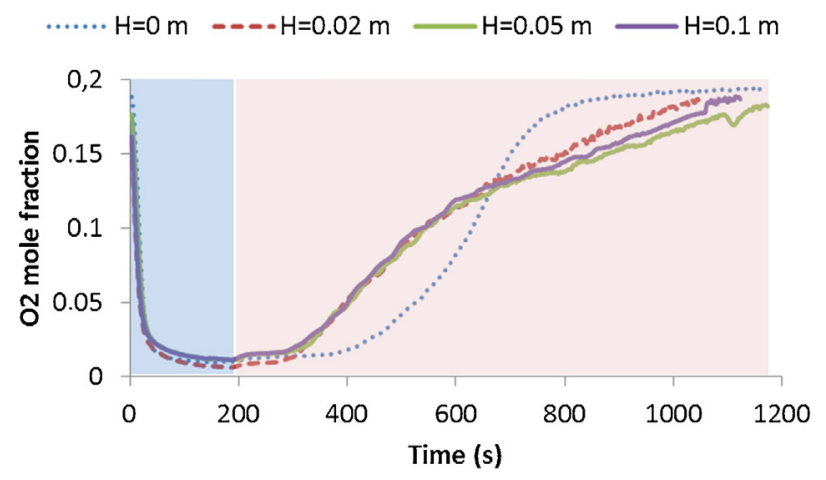

Fig. 7 - The $\mathrm{O}_{2}$ mole fraction as a function of time across the redox cycle: effect of the concentrated air injection at different axial positions. The blue area represents the reduction stage, while the pink area represents the OXI stage (the OXI stage includes both oxidation and heat removal stages). (For interpretation of the references to color in this figure legend, the reader is referred to the web version of this article.)

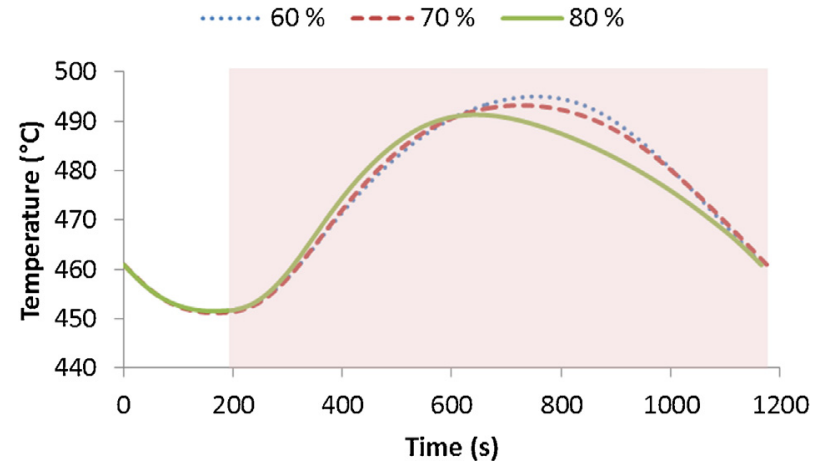

Fig. 8 - Transient temperature across the redox cycle: effect of the percentage of the concentrated air injection; $H=0.1 \mathrm{~m}$. The blue area represents the reduction stage, while the pink area represents the OXI stage (the OXI stage includes both oxidation and heat removal stages). (For interpretation of the references to color in this figure legend, the reader is referred to the web version of this article.)

resulting in a higher degree of oxygen carrier conversion in the $\mathrm{O}_{2}$-rich central plume could further enhance the $\mathrm{O}_{2}$ slip.

This result achieved in the pseudo-2D reactor is promising and suggests that application of this methodology in a 3D reactor (where the concentrated air injection can be injected directly upwards and where the gas will have an additional degree of freedom to slip past the solids) could result in even greater minimization of the temperature rise. As demonstrated, the bubble-to-emulsion mass transfer limitation that is created by concentrated reactant injection can be further enhanced in the 3D configuration by other hydrodynamic effects such as a reduced gas residence time and reduced gas back-mixing.

4.2.1.2. aEffect of the injection percentage. The second factor which could affect the reactor performance with the concentrated air injection heat management technique is the percentage of the injected amount through the secondary injection point relative to the total air feed. This was investigated by varying the injected amount between 60 and $80 \%$. The transient temperature was found to be slightly affected by the injected percentage; the maximum of the temperature tends to shift to the left when increasing the injected percentage, implying that the maximum temperature is reached faster when the injected percentage is increased (Fig. 8). Increased concentrated injection also slightly reduces the temperature variation over the cycle.

This trend can be explained by Fig. 9, where the expected trend of increased $\mathrm{O}_{2}$ slippage with an increase in the percentage of air fed through the concentrated injection is observed. Naturally, the temperature will peak once the heat removal by the cold air stream (together with the heat losses) exceeds the heat generation from the oxidation reaction. Increased oxygen concentration above the bed implies that less reaction is taking place and that the time until the heat generation becomes smaller than the heat removal becomes shorter as the percentage of air fed through the concentrated injection is increased.

\subsubsection{Comparison of heat management techniques}

This section will present and discuss the performance of the different heat management techniques described at the start of Section 4.2 by comparing their corresponding transient 


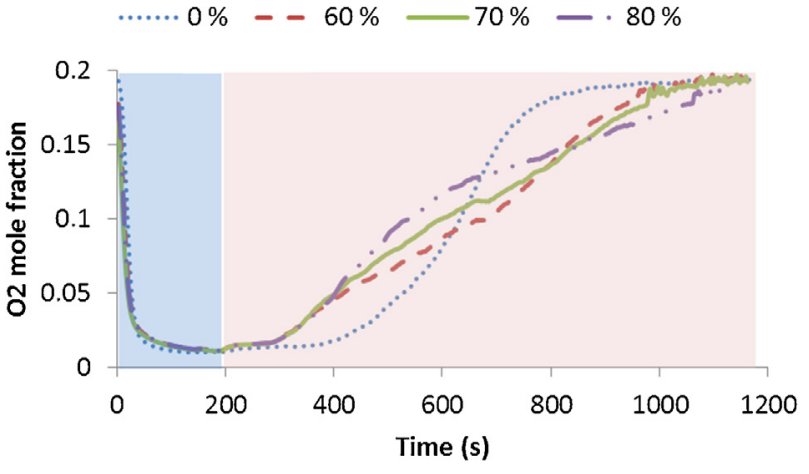

Fig. 9 - Transient $\mathrm{O}_{2}$ mole fraction across the redox cycle: effect of the percentage of the concentrated air injection; $H=0.1 \mathrm{~m}$. The blue area represents the reduction stage, while the pink area represents the OXI stage (the OXI stage includes both oxidation and heat removal stages). (For interpretation of the references to color in this figure legend, the reader is referred to the web version of this article.)

temperature and $\mathrm{O}_{2}$ mole fraction profiles. The results from the reference case are used as a basis for comparison.

For case 1, air was diluted with $36 \%$ nitrogen along the whole OXI stage. The resulting transient temperature profile (Fig. 10) shows a gradual increase of the temperature during the oxidation stage with a shift of the maximum temperature in the cycle toward the end of the OXI stage. This resulted in a reduction of the temperature rise by two thirds compared to the reference case.

Case 2 is designed to obtain a temperature profile with a prolonged constant maximum temperature during the OXI stage combined with reduced temperature rise. This has been achieved by feeding pure air in the first $120 \mathrm{~s}$ of the OXI stage to quickly reach the targeted maximum temperature. The air feed was then diluted with $44 \%$ nitrogen in order to maintain the temperature within $2{ }^{\circ} \mathrm{C}$ variation. Pure air was fed again when the temperature dropped below $2^{\circ} \mathrm{C}$ from the maximum (the second pure air feed is visible on the transient $\mathrm{O}_{2}$ mole fraction profile for case 2 in Fig. 11). This resulted in prolonging the temperature plateau for another $150 \mathrm{~s}$ before the temperature starts dropping again (Fig. 10).

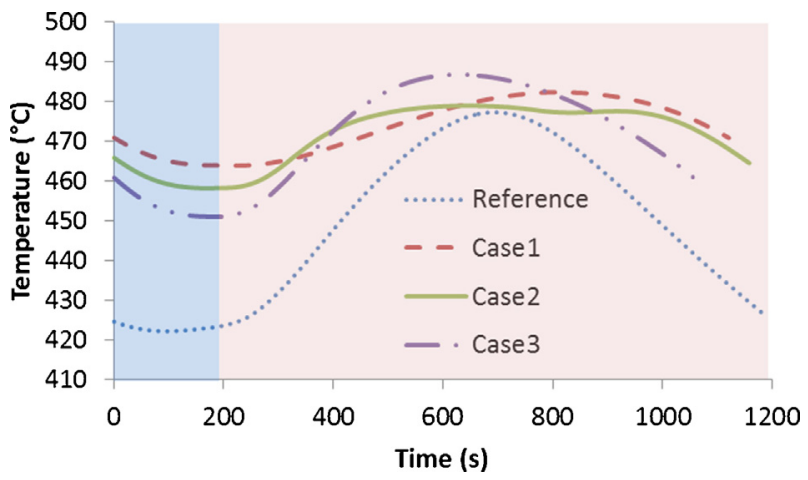

Fig. 10 - Transient temperature across the redox cycle for the three heat management techniques investigated and the reference case. The blue area represents the reduction stage, while the pink area represents the OXI stage (the OXI stage includes both oxidation and heat removal stages). (For interpretation of the references to color in this figure legend, the reader is referred to the web version of this article.)

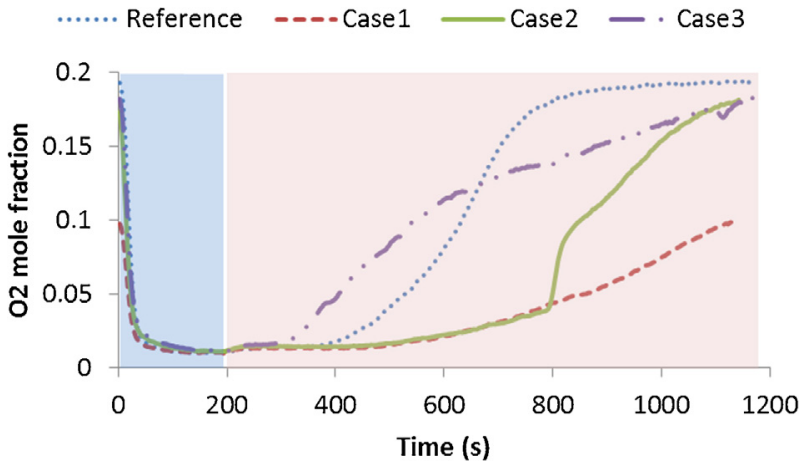

Fig. 11 - Transient $\mathrm{O}_{2}$ mole fraction across the redox cycle for the three heat management techniques investigated and the reference case. The blue area represents the reduction stage, while the pink area represents the OXI stage (the OXI stage includes both oxidation and heat removal stages). (For interpretation of the references to color in this figure legend, the reader is referred to the web version of this article.)

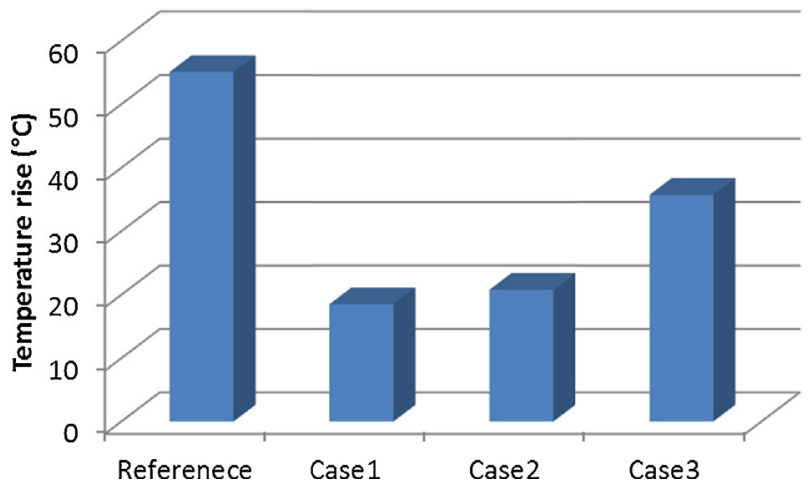

Fig. 12 - Temperature rise in the oxidation stage obtained by the different heat management techniques and the reference case. Note that case 1 refers to constant $\mathbf{N}_{2}$ addition, case 2 to optimized $\mathrm{N}_{2}$ addition and case 3 to concentrated air injection.

All three heat management techniques succeeded to substantially reduce the temperature variation across the cycle in the oxidation stage although with different levels as shown in Fig. 12. Case 1 with constant air dilution with nitrogen resulted in the best performance; the temperature rise reduced by more than two thirds compared to the reference case, where no heat management is applied. Case 2 which involves partial dilution with nitrogen in the middle of the OXI stage, resulted in the second best performance with a slight difference compared to case 1 . This is because the total air dilution is only $26.4 \%$ which is smaller than case 1 . Case 3 which involves secondary concentrated air injection has resulted in slightly lower than $50 \%$ reduction in the temperature rise compared to the reference case. In general, the three heat management techniques proved to be technically feasible, but involve different levels of complexity.

\subsection{Discussion}

Although the first two heat management techniques, cases 1 and 2, showed better performances in terms of temperature rise reduction, case 3 still holds great potential for process simplification. Case 1 and case 2 require recirculation of depleted air which will substantially increase process 
complexity and cost, while case 3 can be achieved with a relatively simple reactor modification. Additionally, case 2 involves some more operational and implementation complexities especially related to operation in a cluster of reactors. Since the streams of air, nitrogen and fuel coming from the respective compressors must be constant, the sequence of fuel-air- $\mathrm{N}_{2}$-dilution-air must be carefully optimized, thus constraining the operating flexibility of the process.

Case 3, however, does not involve any depleted air recirculation or operational complexities. Furthermore, the technique is easy to implement and manipulate by controlling the distribution of the air through the standard and concentrated injection points. The $50 \%$ reduction in the temperature variation over the cycle demonstrated in this work suggests that performance similar to that achieved in cases 1 and 2 could be achieved in a 3D reactor. A 3D configuration would allow for vertical concentrated gas injection and larger gas slip.

Successful demonstration of case 3 in a 3D reactor would pave the way for highly efficient power generation from the simple GSC concept. Following this step, the primary remaining uncertainties are the feasibility of an outlet reactor valve which can operate at the high temperatures and pressures required for efficient power production using a combined cycle and the removal of fines which could damage the downstream gas turbine. If these challenges can be overcome, the simplified standalone nature of the GSC reactor would allow for rapid and efficient scale-up and eventual commercialization of highly efficient second generation $\mathrm{CO}_{2}$ capture technology.

\section{Conclusion}

The novel Gas Switching Combustion reactor concept has been further investigated in this paper in order to define operational strategies for reactor control; this includes controlling the temperature variation across the redox cycle and the oxi/red time which determines the total number of GSC reactors in the cluster to be integrated into a power plant.

The GSC concept uses a single reactor, where a bed of oxygen carrier undergoes redox reactions by alternating air and fuel feeds. This configuration greatly simplifies reactor design, scale-up and operation relative to the conventional looping concept, but standard operating strategies result in substantial temperature variations across the redox cycle. Such large temperature variations cause a reduction in the power plant electric efficiency and can shorten the turbine lifetime when the GSC concept is integrated into a combined cycle. Three different heat management techniques have been devised as solutions for decreasing the temperature rise: the first two techniques involve constant and intermittent dilution of the air feed during the oxidation stage in order to reduce the heat release rate. The third technique uses a secondary concentrated injection point in order to achieve increased $\mathrm{O}_{2}$ slip during oxidation, thus limiting the exothermic oxidation reaction.

The three heat management techniques have been implemented and tested experimentally together with a methodology for controlling the oxi/red time ratio. The two strategies involving dilution of the air feed resulted in the best performance with two thirds temperature rise reduction while the third technique with the secondary concentrated gas injection achieved about 50\% reduction. The advantage of the concentrated gas injection over the air dilution is that it will not require a large depleted air recirculation stream in the full scale GSC power plant. Given the possibility that this option will perform just as well as the diluted air stream in a 3D reactor, it appears to be a promising option for high efficiency power production while maintaining the attractive process simplicity of the GSC concept.

As for the oxi/red time ratio, both the heat balance calculations and the experimental study have proven the feasibility to control this parameter by changing the fuel flow rate while maintaining the air flow rate at the maximum value. The expected linear relationship between the oxi/red time ratio and the fuel/air flow rate ratio was confirmed experimentally implying that a desired oxi/red time ratio could be easily achieved by setting the right fuel/air flow rate ratio.

The approaches demonstrated experimentally in this paper can be utilized to define an optimized configuration for high electric plant efficiency and minimal process complexity. In this way, the GSC concept has great potential to drive faster industrial deployment of 2 nd generation $\mathrm{CO}_{2}$ capture technology.

\section{Acknowledgements}

The authors would like to acknowledge the funding received from the Research Council of Norway which enabled the completion of this work under the project FLOW@CLC. Joost Kors is acknowledged for constructing and maintaining the experimental setup. Paul Hamers is acknowledged for his technical support with the Mass Spectrometer.

\section{References}

Adanez, J., Abad, A., Garcia-Labiano, F., Gayan, P., de Diego, L.F., 2012. Progress in chemical-looping combustion and reforming technologies. Prog. Energy Combust. Sci. 38 (2), 215-282.

Bi, H.T., Grace, J.R., 1995. Flow regime diagrams for gas-solid fluidization and upward transport. Int. J. Multiphase Flow 21 (6), 1229-1236.

Bolhar-Nordenkampf, J., Proll, T., Kolbitsch, P., Hofbauer, H., 2009. Performance of a NiO-based oxygen carrier for chemical looping combustion and reforming in a $120 \mathrm{~kW}$ unit. In: Gale, J., Herzog, H., Braitsch, J. (Eds.), Greenhouse Gas Control Technologies 9. , pp. 19-25.

Butt, T.E., Giddings, R.D., Jones, K.G., 2012. Environmental sustainability and climate change mitigation-CCS technology, better having it than not having it at all. Environ. Prog. Sustain. Energy 31 (4), 642-649.

Cho, P., Mattisson, T., Lyngfelt, A., 2004. Comparison of iron-, nickel-, copper- and manganese-based oxygen carriers for chemical-looping combustion. Fuel 83 (9), 1215-1225.

Cloete, S., Zaabout, A., Johansen, S.T., Annaland, M.v.S., Gallucci, F., Amini, S., 2013. The generality of the standard 2D TFM approach in predicting bubbling fluidized bed hydrodynamics. Powder Technol. 235, 735-746.

Cloete, S., Romano, M.C., Chiesa, P., Lozza, G., Amini, S., $2015 a$. Integration of a Gas Switching Combustion (GSC) system in integrated gasification combined cycles. Int. J. Greenh. Gas Control 42, 340-356.

Cloete, S., Zaabout, A., Romano, M.C., Chiesa, P., Lozza, G., Gallucci, F., Annaland, M.v.S., Amini, S., 2015b. Heat management in Gas Switching Combustion for power production with integrated $\mathrm{CO}_{2}$ capture. In: 7th International Conference on Applied Energy - ICAE2015, Abu Dhabi, United Arab Emirates.

Cloete, S., Zaabout, A., Romano, M.C., Chiesa, P., Lozza, G., Gallucci, F., Annaland, M.v.S., Amini, S., 2015c. Heat management in gas switching combustion for power 
production with integrated $\mathrm{CO}_{2}$ capture. Energy Proc. 75, 2215-2220.

Cuadrat, A., Abad, A., Adánez, J., de Diego, L.F., García-Labiano, F., Gayán, P., 2012. Behavior of ilmenite as oxygen carrier in chemical-looping combustion. Fuel Process. Technol. 94 (1), 101-112.

Ding, N., Wang, W.R., Zheng, Y., Luo, C., Fu, P.F., Zheng, C.G., 2012. Development and testing of an interconnected fluidized-bed system for chemical looping combustion. Chem. Eng. Technol. 35 (3), 532-538.

Erlach, B., Schmidt, M., Tsatsaronis, G., 2011. Comparison of carbon capture IGCC with pre-combustion decarbonisation and with chemical-looping combustion. Energy 36 (6), 3804-3815.

Gallucci, F., van Sint Annaland, M., 2011. A review on recent patents on chemical and calcium looping processes. Recent Patents Chem. Eng. 4 (3), 280-290.

Gallucci, F., Hamers, H.P., van Zanten, M., van Sint Annaland, M., 2015. Experimental demonstration of chemical-looping combustion of syngas in packed bed reactors with ilmenite. Chem. Eng. J. 274, 156-168.

Hakonsen, S.F., Blom, R., 2011. Chemical looping combustion in a rotating bed reactor - finding optimal process conditions for prototype reactor. Environ. Sci. Technol. 45 (22), 9619-9626.

Hamers, H.P., Gallucci, F., Cobden, P.D., Kimball, E., van Sint Annaland, M., 2013. A novel reactor configuration for packed bed chemical-looping combustion of syngas. Int. J. Greenh. Gas Control 16 (0), 1-12.

Hossain, M.M., de Lasa, H.I., 2008. Chemical-looping combustion (CLC) for inherent $\mathrm{CO}_{2}$ separations - a review. Chem. Eng. Sci. 63 (18), 4433-4451.

IPCC, 2007. Climate Change 2007: Mitigation of Climate Change. Cambridge University Press.

Ishida, M., Zheng, D., Akehata, T., 1987. Evaluation of a chemical-looping-combustion power-generation system by graphic exergy analysis. Energy 12 (2), 147-154.

Johansson, E., Mattisson, T., Lyngfelt, A., Thunman, H., 2006. A $300 \mathrm{~W}$ laboratory reactor system for chemical-looping combustion with particle circulation. Fuel 85 (10-11), 1428-1438.

Kolbitsch, P., Bolhar-Nordenkampf, J., Proell, T., Hofbauer, H., 2010. Operating experience with chemical looping combustion in a $120 \mathrm{~kW}$ dual circulating fluidized bed (DCFB) unit. Int. J. Greenh. Gas Control 4 (2), 180-185.

Kronberger, B., Johansson, E., Loffler, G., Mattisson, T., Lyngfelt, A., Hofbauer, H., 2004. A two-compartment fluidized bed reactor for $\mathrm{CO}_{2}$ capture by chemical-looping combustion. Chem. Eng. Technol. 27 (12), 1318-1326.
Linderholm, C., Abad, A., Mattisson, T., Lynyfelt, A., 2008. $160 \mathrm{~h}$ of chemical-looping combustion in a $10 \mathrm{~kW}$ reactor system with a NiO-based oxygen carrier. Int. J. Greenh. Gas Control 2 (4), 520-530,

Lyngfelt, A., Leckner, B., Mattisson, T., 2001. A fluidized-bed combustion process with inherent $\mathrm{CO}_{2}$ separation; application of chemical-looping combustion. Chem. Eng. Sci. 56 (10), 3101-3113.

Metz, B., Davidson, O., Coninck, H.D., Loos, M., Meyer, L., 2005. Carbon Capture and Storage. Intergovernmental Panel on Climate Change.

Noorman, S., van Sint Annaland, M., Kuipers, 2007. Packed bed reactor technology for chemical-looping combustion. Ind. Eng. Chem. Res. 46 (12), 4212-4220.

Proell, T., Kolbitsch, P., Bolhar-Nordenkampf, J., Hofbauer, H., 2009. A novel dual circulating fluidized bed system for chemical looping processes. AIChE J. 55 (12), 3255-3266.

Robie, R.A., Hemingway, B.S., 1995. Thermodynamic Properties of Minerals and Related Substances at $298.15 \mathrm{~K}$ and 1 bar Pressure and at Higher Temperatures. U.S. Geological Survey Bulletin 2131, Washington.

Spallina, V., Romano, M.C., Chiesa, P., Gallucci, F., Annaland, M.v.S., Lozza, G., 2014. Integration of coal gasification and packed bed CLC for high efficiency and near-zero emission power generation. Int. J. Greenh. Gas Control 27, 28-41.

Zaabout, A., Cloete, S., Johansen, S.T., Annaland, M.v.S., Gallucci, F., Amini, S., 2013. Experimental demonstration of a novel gas switching combustion reactor for power production with integrated $\mathrm{CO}_{2}$ capture. Ind. Eng. Chem. Res. 52 (39), 14241-14250.

Zaabout, A., Cloete, S., Amini, S., 2014a. Hydrodynamic investigation into a novel IC-CLC reactor concept for power production with integrated $\mathrm{CO}_{2}$ capture. In: 10th International Conference on Computational Fluid Dynamics in the Oil \& Gas, Metallurgical and Process Industries, Trondheim, Norway.

Zaabout, A., Cloete, S., Amini, S., 2014b. Operating experience with a high-temperature pseudo-2D fluidized bed reactor designed especially for detailed local data collection. In: 10th International Conference on Computational Fluid Dynamics in the Oil \& Gas, Metallurgical and Process Industries, Trondheim, Norway.

Zaabout, A., Cloete, S., Annaland, M.v.S., Gallucci, F., Amini, S., 2015. A novel gas switching combustion reactor for power production with integrated $\mathrm{CO}_{2}$ capture: sensitivity to the fuel and oxygen carrier types. Int. J. Greenh. Gas Control 39, 185-193. 